\title{
Sociología del mal y teodicea en Las Formas Elementales de la Vida Religiosa de E. Durkheim
}

\section{Sociology of evil and theodicy in Durkheim's \\ Elementary Forms of Religious Life}

\author{
Ramón RAMOS TORRE \\ Universidad Complutense de Madrid \\ rrt@cps.ucm.es
}

Recibido: 30.01 .2012

Aprobado definitivamente: 17.04.2012

\section{RESUMEN}

Al estudiar los ritos piaculares en Las Formas Elementales de la Vida Religiosa Durkheim esboza una sociología del mal de interés general. Esa sociología concibe el mal como un hecho social y explica los ritos de duelo y expiación, la creencia en poderes malignos y la purgación ritual del mal. Durkheim relaciona el mal con la ambigüedad de lo sagrado, lo que produce serias tensiones en su sistema teórico. También aborda el problema de la teodicea para el que propone una solución laica en forma de una sociodicea fundamentada en términos funcionalistas.

Palabras Clave: Durkheim; Ambigüedad de lo sagrado; Ritos piaculares; Sociología del mal; Teodicea

\begin{abstract}
In his analysis of piaculiar rites in The Elementary Forms of Religious Life, Durkheim outlines a sociology of evil of general interest. This sociology conceives evil as a social fact and explains the rites of mourning and atonement, the belief in malignant powers and the ritual purge of evil. Durkheim relates evil with the ambiguity of the sacred, causing serious tensions in his theoretical system. He also addresses the problem of theodicy for which he proposes a lay solution in the form of a functional based sociodicy.
\end{abstract}

Keywords: Durkheim; Piacular rites; Ambiguity of the sacred; Sociology of evil; Theodicy

\section{SUMARIO}

1. Sobre los ritos piaculares. 2. La ambigüedad de lo sagrado. 3. El problema de la teodicea. 4. Conclusiones. 
Ellos tenían cantos justos para las pasiones del alma, algunos para las debilidades y otros para las iras, a través de los cuales, al excitar y suscitar las pasiones según una justa medida, se las tornaba proporcionadas a una valerosa virtud Jámblico, Vida de Pitágoras

Las heridas del espíritu se curan y no dejan cicatrices.

Hegel

Hace unos años, Jeffrey Alexander (2003) llamaba la atención sobre la sorprendente ausencia de una sociología del mal que abordara en serio su estudio, no ya como problema periférico o incluso como indicador de la ausencia o de la falta de sociedad, sino como algo que es consustancial a toda vida social $\mathrm{y}$, en consecuencia, a sus posibles sociologías ${ }^{1}$. Ya mucho antes, a finales de la década de los '60 del pasado siglo, un lector tan atento de la tradición clásica como Peter Berger (1971: 71-103) había destacado la relevancia sociológica del problema de la teodicea. Si el centro del análisis sociológico es la constitución y mantenimiento del nomos, argumentaba, entonces todo orden social ha de dar cuenta de sus desviaciones y quiebras y, consecuentemente, proceder a justificarlas, es decir, a construir el equivalente de lo que teólogos y moralistas llamaron, desde los tiempos de Leibniz, una teodicea. En la estela de esta idea algunos, como Morgan y Wilkinson (2001), han afinado más y propuesto considerar el problema moderno de la sociodicea, es decir, de la justificación social del mal y del sufrimiento humanos más allá de los designios de un dios o una naturaleza trascendentes; es la sociedad, son sus códigos culturales, son las justificaciones de sus complejos normativos los que típicamente abordan y dan cuenta del mal que, por el hecho de vivir juntos, no dejamos de padecer. Y no se limitan a eso, pues de la mano de la detección y explicación del mal viene la fijación de los modos de lidiarlo, evitarlo o erradicarlo -una sociodicea comporta siempre una tecnología de administración del mal.

Sociología del mal, teodicea, sociodicea: he aquí tres temas densamente interrelacionados en los que merece la pena detenerse. La celebración del primer centenario de la publicación de Las Formas Elementales de la Vida Religiosa (Durkheim, 1912 [1968]; en adelante FE) es una buena ocasión para rastrearlos aunque sólo sea en el espacio circunscrito de un autor y una de sus obras. La empresa no es novedosa. Ya sea Alexander (2003), ya Wilkinson (2005), ya especialmente Rosati (2005, 2008a y 2008b), en la estela de los trabajos de Pickering (1979, 2009 [1984], 2004 y 2008): muchos son los 'rescatadores' actuales de Durkheim que han llamado la atención sobre la relevancia de su sociología del mal y del sufrimiento ${ }^{2}$, destacando siempre la importancia de su último gran libro para reconstruirla.

Asumiendo esa tarea de rastrear una obra a la búsqueda de un tema crucial y elusivo a la vez, en este artículo (1) dedicaré un primer epígrafe a una lectura cuidadosa de capítulo dedicado en FE a la descripción y explicación de los ritos piaculares, para abordar a continuación (2) el problema de lo que, en seguimiento de Robertson Smith, Durkheim denominaba la ambigüedad de lo sagrado, lo que permitirá pasar a (3) reconstruir el problema de la teodicea/sociodicea tal como aparece, a veces simplemente aludido o esbozado, en FE, para alcanzar un epígrafe final (4) en el que se fijarán las conclusiones que se alcanzan una vez completado el recorrido.

\section{SOBRE LOS RITOS PIACULARES}

Los ritos piaculares son descritos y analizados en el capítulo 5 del Libro III de FE, como cierre y final del análisis de "las principales actitudes rituales" (FE: 425 y ss.) del totemismo australiano. Su estudio no ocupa muchas páginas (FE: 557-592), pero cumple un papel de primer orden en la arquitectura de la obra, ya sea porque cierra el análisis de las prácticas rituales que, según se encarga Durkheim de subrayar en las Conclusiones (FE: 595 ss.) y habrá ocasión de comprobar más adelante, constituyen el núcleo de toda religión, ya porque replantea la noción de lo sagrado, central en toda su sociología de la religión, ya

\footnotetext{
${ }^{1}$ En el mismo sentido Das (1997), Morgan (2002) y Wolff (1969).

${ }^{2}$ Véanse especialmente los estudios recogidos en el libro editado por Pickering y Rosati (2008), además de los trabajos de Arppe (1995) y Ramp (2008a y 2008b).
} 
porque se adentra en el análisis del mal, completando esa sociología de lo patológico y del sufrimiento que había alcanzado un papel tan importante en sus obras anteriores -tanto en De la División del Trabajo Social(1893), como en Las Reglas del Método Sociológico (1895) o, evidentemente, en El Suicidio (1897)- y que, como es notorio, constituye a la vez punto de arranque del logos que se encarna en la ciencia social y hueso durísimo de roer para una sociología que, como diagnosticara en imagen acertada Luhmann (1982: 9), tiende a ocultar o neutralizar las flores del mal.

Los ritos piaculares son presentados como una variante del culto positivo. Desde este punto de vista están emparentados con las otras variantes positivas consideradas. Todas ellas regulan y organizan "las relaciones positivas y bilaterales" que los fieles mantienen con las fuerzas religiosas -a diferencia de los ritos negativos, orientados a asegurar la "abstención de cualquier contacto" entre ambos ( $F E$ : 464). Con todo, en alguno de sus aspectos -sobre todo en lo que se refiere al papel que en ellos desempeña el dolor y el sufrimiento ( $F E$ : 490)- están también emparentados con los ritos ascéticos, aun cuando esta semejanza parcial no debe ocultar sus diferencias -como se comprobará más adelante.

"Piaculaire" es un término que aparece ya en textos franceses del XVI y es recogido en el Dictionnaire de l'Académie Française de 1762. En la época en la que escribe Durkheim era poco utilizado, habiendo sido reemplazado por el adjetivo 'expiatorio's. Proviene del latín piaculum que significa tanto expiación, como medio de expiación y sacrificio expiatorio; en alguno de sus usos (por ejemplo en Plinio), el término también hace referencia a calamidades y desgracias ${ }^{4}$. El piaculum y los términos de los que deriva y en los que se proyecta hacen referencia a una expiación ritual requerida por alguna falta en contra de la pietas debida a los dioses, los ancestros y la comunidad política, falta que puede ser puramente ritual y que puede también estar relacionada con el sufrimiento de calamidades o desgracias individuales o grupales. En todos los casos el objetivo de la celebración del piaculum es conseguir la reconciliación de los humanos con los dioses y los ancestros que protegen a la comunidad y aseguran la armonía cósmico-social. Esa reconciliación se logra por medios rituales.

Durkheim confiesa no sentirse limitado por el uso latino del término y propone un significado que, aunque es acorde en lo sustancial, resulta más amplio. "Toda desgracia, todo lo que es de mal augurio, todo lo que inspira sentimientos de angustia o de temor necesita un piaculum y, en consecuencia, es llamado piacular" (FE: 557). No se trata, pues, tan sólo de faltas rituales o de incumplimientos contrarios a la pietas debida a dioses, ancestros y comunidad, sino de la experiencia del mal en sus distintas versiones -desgracia efectiva, simple temor o mal augurio. Y así, al establecer la lista de las circunstancias en las que se celebran los ritos piaculares, muestra que no sólo ocurren en ocasión de faltas rituales o de profanación, pérdida o sustracción de objetos sagrados, sino también cuando muere un miembro del grupo, cuando ocurren fenómenos naturales atípicos y sobrecogedores, como una aurora austral, o ante calamidades naturales como sequías, inundaciones, malas cosechas, escasez de caza (FE: 557 y $576-80)^{5}$. Todos estos casos producen la experiencia colectiva del mal y desatan la necesidad de un ritual piacular.

El ritual piacular durkheimiano supone la conjunción de dos rituales que podrían ser diferenciados, aunque Durkheim no los separe ni analítica ni realmente. Por un lado, es un ritual de duelo que, ante una desgracia, expresa y dramatiza el sufrimiento colectivo en manifestaciones extremadas de dolor e incluso de violencia (contra uno mismo, contra los demás o contra un chivo expiatorio) ( $F E$ : 558-66 y 573). Por el otro lado, es un ritual de expiación propiamente dicha, en cuyo curso se alcanza la

\footnotetext{
${ }^{3}$ En el diccionario de la Academia Francesa de 1835 se dice ya que es un término poco utilizado; este juicio lo reiteran el diccionario de Émile Littré de 1863-77 -que apunta que solo se utiliza para referirse a la Antigüedad- y la $8^{\text {a }}$ edición del diccionario de la Academia Francesa de 1932-35. En español, piacular es un neologismo no reconocido en la RAE ni en los diccionarios de uso

${ }^{4}$ Piaculum deriva etimológicamente de pius (aquel que reconoce y cumple con sus deberes para con los dioses, los ancestros, la patria, etc.) y pietas (sentimiento de reconocimiento de los deberes para con los dioses, los ancestros, la patria, etc.) y se relaciona con piamen (sacrificio expiatorio), piamentum (expiación, víctima expiatoria), piatio (expiación) y piator (sacerdote que celebra las ceremonias expiatorias), términos que en las lenguas romances han originado la familia de términos relacionados con 'expiación'.

${ }^{5} \mathrm{Se}$ trata de los casos que provocan rituales piaculares entre las tribus australianas cuya etnografía se utiliza en FE, sin ninguna pretensión de agotar los casos en otras religiones. Durkheim destaca (FE: 580) que esos rituales parecen escasos en número y de una importancia limitada entre los australianos, lo que no limita su relevancia social ni sociológica: lo importante es que existan como tipo distintos, no su frecuencia.
} 
purificación de lo que estaba contaminado y causaba sufrimiento. La unión de ambos componentes lleva a la inversión de una situación inicial de desgracia y dolor en otra de purificación y reconciliación con el mundo y sus dioses, restaurando así en el grupo la confianza y seguridad perdidas.

Durkheim es prolijo en la etnografía de esos rituales, pero no es ésta la que me propongo reconstruir. Su descripción cuidadosa de las ceremonias es también el punto de partida para el esbozo de una sociología del mal que es la que aquí interesa. Se estructura a partir de tres preguntas entrelazadas: a. ¿por qué los rituales piaculares son colectivos, aun cuando la desgracia pueda no afectar (o afectar en grado distinto) a todos los miembros de la colectividad?; b. ¿de dónde vienen y cómo se configuran esas fuerzas maléficas que provocan las desgracias, cuyo dolor se dramatiza en los rituales de duelo?; c. ¿cómo se convierten las fuerzas maléficas en benéficas y el duelo en expiación liberadora? La respuesta a estas tres preguntas constituye el núcleo o principal aportación de la sociología del mal de $F E$. Se despliega en forma de tres argumentos: el primero es tópicamente durkheimiano; el segundo y el tercero vienen de la mano de novedades analíticas de la sociología de la religión propia de $F E$. Voy a reconstruirlos uno por uno en lo que sigue.

El primer argumento lo podría predecir cualquier lector de las Reglas del Método Sociológico. En efecto, reiterando el discurso que hace de la constricción el signo de lo social y la clave del análisis sociológico, Durkheim se limita a subrayar que las prácticas colectivas en las que se materializan los ritos piaculares no resultan de la suma azarosa y singular de decisiones individuales, ni dependen por lo tanto de los sentimientos particulares de duelo o de los deseos de liberación que pueden sentir unos individuos y otros no. Son, por el contrario, obligatorias, producto de la constricción que el grupo ejerce sobre sus miembros (FE: 567-8), de la "presión" social irresistible que se desata en razón de la circunstancia desgraciada que se atraviesa (FE: 589). ¿Por qué esa presión social? La razón es de orden funcional: si el grupo no se mostrara unánime en la expresión fehaciente de dolor ante las desgracias que algunos de sus miembros sufren, no podría mantenerse como tal y acabaría víctima de la entropía ${ }^{6}$ que amenaza a todo orden social. Para hacerlo más visible, Durkheim ejemplifica el argumento general en el caso de la familia:

"Una familia que tolere que uno de los suyos pueda morir sin ser llorado testimonia su falta de unidad moral y de cohesión: abdica, renuncia a ser" (FE: 571).

El dolor puede ser que sea sentido, pero aun en mayor medida su expresión es debida y, además, en la forma pre-fijada por el ritual; si no se expresara, o lo fuera de una forma desviada, se desatarían sanciones reales y simbólicas para restituir la unidad del grupo. No se gime, ni se gime con una específica gestualidad, porque eso sea lo que espontáneamente se siente, sino porque está prescrito $\mathrm{y}$, además, de una forma concreta; de ahí la ritualización de los sentimientos.

La sociología del mal implícita en este primer argumento propone, pues, como tesis general y fundacional que el mal que aborda es social o colectivo. En términos triviales esto supone que son los grupos los que delimitan qué es el mal -en el doble sentido de en qué fenómenos se manifiesta y cuál es su semántica- y qué hay que hacer, cuando ocurre, para paliarlo, compensarlo, congelarlo temporalmente o erradicarlo. Esta respuesta supone siempre, como habrá ocasión de comprobar con más detenimiento, ritualización. Pero yendo más allá $-\mathrm{y}$ conectando con propuestas de Alexander ${ }^{7}$ - propone, además, que toda agrupación humana, al constituirse o al reproducirse o mantenerse, define y delimita los males a los que se enfrenta y, en relación a los cuales, es o lucha por ser. Desde este punto de vista, el mal no es marginal o defectivo (es decir: ausencia o falta de sociedad), ni es algo que simplemente sobreviene y

\footnotetext{
${ }^{6}$ Evidentemente Durkheim no utiliza el término entropía, a pesar de la relevancia del paradigma fisicalista en la poética de FE: todo en esa obra son fuerzas, corrientes eléctricas, energías emergentes y degradadas, presiones, etc. (Véase Ramos 2010: 399) Con todo, el argumento fundamental que avisa sobre la exposición de toda institución social a una entropía que sólo puede remediarse ritualmente es reiterado en las páginas de FE. Como simple muestra valga la siguiente:”todas las fuerzas, incluso las más espirituales, se degradan a causa del tiempo si nada acude a proporcionarles la energía que pierden por el curso natural de las cosas" (FE: 482).

${ }^{7}$ En su proyecto de esbozar una sociología del mal de inspiración durkheimiana, Alexander propone: "las sociedades construyen el mal de forma que pueda haber un castigo, pues son la construcción de, y la respuesta a, el mal las que definen y vigorizan el bien. [...] Sin la imaginación y la identificación social del mal no habría espacio para esa adhesión al bien que los moralistas propugnan con tanta fuerza" (Alexander 2003: 296-7).
} 
entonces desata una reacción, sino una precondición del grupo: somos no sólo el bien que apetecemos, sino el mal o los males que conjuramos y enfrentamos; los males que tememos y a los que nos enfrentamos nos sostienen y definen; nada o poco seríamos sin ellos.

El segundo argumento es ya más propio del nuevo marco analítico que se desarrolla en $F E$. Combina la idea de la primacía de la práctica social, como acción emocional o afectiva, con la de la hipóstasis de lo sagrado. La pregunta que se quiere contestar es: ¿por qué los practicantes de un ritual de duelo se creen enfrentados a fuerzas maléficas a las que de alguna manera se imputan las desgracias y contra las que se lucha o a las que se intenta aplacar? ¿Por qué el muerto que lloramos parece pedir venganza y responsabilizarnos de su muerte? Eso es lo que consideran los creyentes que imputan a la cólera de dioses o a la malevolencia de fuerzas (cósmicas o personales) las desgracias. Como dicta su ortodoxia metodológica, la respuesta de Durkheim se enfrenta a la conciencia ingenua y errónea del creyente, ya que a los actores inmediatos, nos asegura, no hay que reconocerles ningún privilegio $\operatorname{cognitivo}(F E$ : 597).

Su alternativa invierte, pues, la comprensión del mal que alcanzan los actores inmediatos: no son los dioses o los poderes maléficos los que provocan los ritos, sino justamente al revés: "los poderes malvados son producto y símbolo de esos ritos [piaculares]" (FE: 589). En lo esencial, el argumento se despliega siguiendo esta secuencia: las fuerzas del mal son la personificación de fuerzas colectivas; las fuerzas colectivas son la hipóstasis de emociones colectivas; las emociones colectivas son generadas por la participación de los miembros del grupo en el ritual de duelo; el ritual de duelo es la respuesta colectiva constrictiva a la experiencia de la desgracia.

He aquí una presentación sintética, aunque no completa, del argumento:

"Cuando la sociedad atraviesa circunstancias que la entristecen, la angustian o la irritan, ejerce sobre sus miembros una presión para que testimonien, en actos significativos, su tristeza, su angustia o su ira [...] Es ésta la experiencia que el hombre interpreta al imaginar, por fuera de sí, seres malvados cuya hostilidad, constitutiva o temporal, no puede desarmarse sino por medio del sufrimiento humano. Esos seres no son, pues, más que estados colectivos objetivados; la misma sociedad vista en uno de sus aspectos" ( $F E$ : 589-90).
El relato subyacente ( $F E: 572$ ss.) dice que, en ocasión de la desgracia y en razón del daño sufrido o temido, los seres humanos canalizan ritualmente las emociones negativas (desaliento, temor, tristeza, inseguridad, etc.) entonces desatadas. Esa ritualización comporta un actuar conjunto y al unísono que tiene por efecto agudizar, exacerbar o intensificar los iniciales sentimientos negativos. Por su parte, la intensificación emocional ligada al actuar conjunto lleva a los actores rituales a sentir (como si estuvieran ante) la experiencia de una fuerza o poder malevolente -que en realidad se limita a ser la objetivación de las emociones negativas colectivamente sentidas y colectivamente intensificadas. Esa fuerza colectiva malevolente puede entonces personificarse en seres trascendentales (o trascendentalizados por la misma desgracia, como es el caso de los muertos) que, por razones heterogéneas que habría que desentrañar, provocan la desgracia o buscan hacer daño. Pero se trata de una fuerza que expresa la metamorfosis sufrida por el grupo a consecuencia de sus prácticas y de la explosión emocional que producen. Dicho en fórmula muy concisa que no teme la apariencia de paradoja: "no se llora al muerto porque se le tema, sino que se le teme porque se le llora" (FE: 573); es el sufrimiento colectivo ritualizado el que se objetiva como fuerza y se personalizada como poder malevolente y hostil.

Este argumento se despliega-siguiendo el modelo de análisis propio de la sociología durkheimianaen el triple plano genético (¿cuál es la causa de los poderes malvados?), expresivo (¿qué representan?) $\mathrm{y}$ funcional (¿qué funciones cumplen en el proceso de reproducción social?). La respuesta es siempre la misma: la sociedad, el grupo, la colectividad, la comunidad, la tribu, el clan, etc. Su columna vertebral ensambla tres hipótesis: la que asigna primacía a la práctica o la acción ritual en el análisis sociológico; la que atiende especialmente a los aspectos afectivos (sentimiento, emociones, pasiones) y corporales (cantos, danzas rítmicas, experiencia visual o táctil del otro, etc.) de las prácticas colectivas para dar cuenta de la génesis y reproducción de los grupos sociales; la que subraya la recurrente hipóstasis social de las prácticas y las emociones colectivas como condición para acceder a la comunización de la acción.

Sobre estas tres hipótesis se construye el entramado analítico de $F E^{8}$. Más adelante habrá ocasión de volver sobre ellas. Mientras tanto, se pueden destacar algunas implicaciones de este que he denominado segundo argumento para una sociología durkheimiana del mal. La primera implicación 
es que el enfrentamiento social con el mal procede siempre a su ritualización: nada podemos hacer socialmente con el mal si no ritualizamos nuestra respuesta. Sólo tras la fijación del ritual y atendiendo a sus consecuencias sobre los participantes podremos hablar propiamente del sistema de creencias en el que se expresa. Lo importante es lo que 'se hace' con el mal, no cómo 'se dice'; en definitiva, el problema weberiano del sentido es derivado y secundario - como habrá ocasión de comprobar. Una segunda implicación es que siendo los poderes a los que se imputa el mal resultado de la reacción ritual a la experiencia de la desgracia, los imputados como causantes resultan siempre arbitrarios, pura objetivación o personalización de las emociones colectivas. En consecuencia, la sociología durkheimiana del mal supone la normalidad del fenómeno del chivo expiatorio, es decir, de un sujeto-otro al que arbitrariamente se imputan los males que sufre el grupo y sobre el que se canaliza la ira colectiva. Que su relación con el mal que se le imputa sea arbitraria es lo lógico y esperable desde esta perspectiva. Otra implicación relevante es que, desde el punto de vista que informa el análisis anterior, el mal se ha de abordar atendiendo preferentemente a las emociones que suscita, lo sustentan y lo contrarrestan. Una sociología del mal es así una sociología de las emociones colectivas expresadas y sustentadas ritualmente. Una última implicación es que, si se atiende a Durkheim en sus propios términos, habrá que convenir en que, por muy esclarecida e ilustrada que sea una sociedad, tenderá siempre a concebir el mal como una fuerza exteriorizada y ajena a ella misma, que la acosa y es opaca para los actores que la han generado.

Como ya se anunció antes, el tercer argumento -que se pasa ahora a considerar- es respuesta a la pregunta sobre la sorprendente conversión de las fuerzas o poderes malevolentes en benevolentes y del ritual de duelo en ritual de expiación que borra, limpia o purga. ¿Por qué se apaciguan los dioses o las fuerzas que estaban irritadas y nos enviaban la desgracia? ¿Por qué se reconcilia el muerto con un colectivo que parecía directa o indirectamente objeto de su ira? La respuesta se alcanza en el seno del marco analítico que ha permitido explicar la emergencia ritual de los poderes malevolentes provocadores de las desgracias. En consecuencia, es la acción de los ritos - como prácticas colectivas emocionales generadoras de experiencias que abocan a la hipóstasis- la que explica que el dolor se pueda purgar y los poderes que acosan se conviertan en poderes amigos.

Amante de las formulaciones al borde de la paradoja -como ya ha habido ocasión de comprobar-, Durkheim propone que no importa tanto el objeto al que se dirige al ritual como el hecho de que quienes en él participen se sientan comulgando en un mismo sentimiento. Esa comunión consigue la recuperación del tono vital que parecía perdido.

"Comulgar en la tristeza supone también comulgar, y toda comunión de conciencias, con independencia del tipo que sea, eleva la vitalidad social" (FE: 574$)$.

Lo relevante de los rituales no es si se llora o se ríe, si se conjura la muerte o se celebra la vida, sino el hecho de que los miembros del grupo lo hagan juntos, acompasados, reiterando el contacto de los cuerpos y el ritmo de los movimientos. Visto desde esta perspectiva, el ritual es algo más que lo antes señalado: no se limita a comunizar e intensificar las emociones, sino que, además, restaura el tono vital y el deseo de vivir de los participantes. Durkheim lo enuncia de forma general, haciendo diáfana la conversión del duelo en expiación que libera:

"Incluso cuando las ceremonias religiosas tienen como punto de partida un hecho que inquieta o entristece, conservan su poder de estímulo sobre el estado afectivo del grupo y los individuos. Por el simple hecho de ser colectivas elevan el tono vital. Ahora bien, cuando uno siente en sí la vida -sea en forma de irritación penosa o de alegre entusiasmo- uno no cree en la muerte; en consecuencia recobra la seguridad, recupera el valor y, en términos subjetivos, todo transcurre como si el rito hubiera evitado realmente el peligro que se temía" ( $F E$ : 583; cursiva RR).

La hipérbole es evidente: el ritual parece llevarnos a no creer en la muerte. Pero más allá de esa presentación extremada, lo destacable es que el mismo ritual de duelo se convierta automáticamente en ritual de expiación que purga al alma de inquietudes, inseguridades y temores. El ritual, por el simple hecho de serlo y con independencia de su motivo

\footnotetext{
${ }^{8} \mathrm{He}$ analizado las tres hipótesis en un texto reciente (Ramos 2010: 396 y ss.) a cuyas propuestas y cruciales referencias bibliográficas (que en gran parte suponen una lectura creativa y novedosa de la sociología de Durkheim) me remito. Véanse, además, Bellah (2011), Collins (2009) y Rappaport (2000) que, con grados diferentes de heterodoxia y eclecticismo, siguen y actualizan las propuestas durkheimianas sobre la crucialidad del ritual en la vida social (no sólo religiosa).
} 
o finalidad explícita, es siempre catártico. Los participantes en los rituales durkheimianos son, pues, como los espectadores de la representación trágica de que hablaba Aristóteles. Ciertamente, no se limitan a contemplar un drama que pasa de la felicidad a la desgracia y se recrea mostrándola, sino que son los actores mismos que representan el drama de la desgracia humana -o más bien: el coro que se lamenta y rasga las vestiduras. En cualquier caso, esa participación actúa como una catarsis aristotélica: una purga que limpia el alma del sufrimiento y del miedo y reconstruye la seguridad vital sin la que quedaríamos desvalidos frente al mundo ${ }^{9}$. Asistiendo a una representación trágica, o celebrando junto con nuestros congéneres un rito piacular, nos purgamos del mal porque sentimos y nos sentimos juntos. La expiación ritual borra la falta, purifica lo profanado y reconcilia con los poderes cósmicos que dejan así de ser contrarios a la felicidad de los hombres, convirtiéndose en garantes de un mundo, al fin y al cabo, habitable, amable incluso. Más adelante se podrá comprobar la relevancia de una concepción tal de la función de los rituales en el contexto del problema de la teodicea.

Como es obvio, el marco analítico que permite explicar la doble conversión de la malevolencia en benevolencia y del rito en expiación-purga es el dominante en $F E$ ya antes señalado: primacía de la práctica; énfasis en el carácter emocional de la acción ritual; consideración de la hipóstasis como algo constitutivo de un ritual. El modelo explicativo es idéntico:

"Los poderes bienhechores no se constituyen de manera diferente; resultan de la vida colectiva y la expresan; representan también a la sociedad pero captada en una actitud muy diferente, a saber: en el momento en el que se afirma con confianza y empuja a las cosas con ardor para que concurran a la realización de los fines que persigue" (FE: 590).

La sociología del mal implícita en estas propuestas es obvia. Se enfatiza la centralidad del análisis funcional que permite comprender cuáles son las aportaciones o prestaciones para el mantenimiento o reproducción de la estructura (orden) social que, con independencia de la intención de los participantes, genera la apropiación ritual de la experiencia del mal. Los rituales convierten la aflicción en euforia colectiva por el simple hecho de ser rituales colectivos. De ahí la reiteración implícita de la tesis sobre la que ya se llamó la atención anteriormente. En efecto, el mal no es tanto un disolvente social como un cemento de lo social; al enfrentarlo ritualmente compactamos a un colectivo, que se siente así por encima de la desgracia y la muerte. La sociología durkheimiana del mal nos induce a pensar que aunque el mal esté fuera acechándonos, el grupo cuenta con recursos suficientes para dramatizarlo ritualmente, hacerlo propio y cambiarle el sentido, recuperando así su tono vital y la seguridad cósmico-social.

\section{LA AMBIGÜEDAD DE LO SAGRADO}

Durkheim cierra el estudio de los ritos piaculares adentrándose en lo que acaba resultando una fuente de problemas difíciles de solucionar dentro de sus coordenadas teóricas. Sostiene, en efecto, en la sección última del capítulo ( $F E$ : 584 ss.) que los rituales de duelo y expiación analizados muestran que lo sagrado es ambiguo. Esta idea de la ambigüedad de lo sagrado dice recogerla de Robertson Smith. Con independencia de que sea una idea recibida y sin entrar a sopesar hasta dónde llega la influencia de Robertson Smith tanto en éste como en otros ca$\operatorname{sos}^{10}$, es clara la relevancia del tema para reconstruir la sociología durkheimiana del mal.

¿Qué significa la ambigüedad de lo sagrado? Es notorio que la sociología de la religión de $F E$ se nuclea alrededor de la noción de lo sagrado (Ramos 1999: 200 y ss.). La trabajosa definición que se propone en las páginas iniciales de la obra ( $F E$ : 31-66) así lo muestra: junto con la distinción de las creencias y las prácticas y la remisión a una iglesia o comunidad como soporte de ambas, es la referencia a lo sagrado el núcleo duro del concepto durkheimiano de la religión ${ }^{11}$. Pero ese núcleo no recibe un tratamiento conceptual ordenado y sistemático, sino que es abordado una y mil veces a lo largo de la

\footnotetext{
${ }^{9}$ Sostenía Aristóteles: "La tragedia es imitación de una acción esforzada y completa [...], actuando los personajes y no mediante relato, y que mediante compasión y temor lleva a cabo la purgación de tales afecciones"(Aristóteles, Poética 1449b24-28). Sobre la significación de la catarsis-purgación y las afecciones que se purgan por medio del espectáculo trágico véase García Yebra en Aristóteles (1992: 379-91) y Nussbaum (1995:481-3). Padel (2009: 151 y ss.) destaca la relación entre los rituales de Dionisos, la tragedia y la purificación-catarsis.

${ }^{10}$ Sobre la influencia de Robertson Smith hay una abundante literatura; consúltense Jones (1977 y 1986), Segal (2002), Strenski (1998). No voy a entrar en ese tema, que ya abordé parcialmente en Ramos (1999: 185-7)
} 
obra, de forma que su semántica ha de ser reconstruida con cuidado y trabajo. Sólo en el marco de un estudio monográfico sobre el tema se podría dar cuenta de los planos semánticos de lo sagrado y de sus eventuales tensiones. Como no es ésa la intención de este trabajo, me limitaré a atender a los rasgos pertinentes para el caso. Son los siguientes:

a. Lo sagrado es el resultado de una distinción que lo separa en términos de antagonismo de su antónimo, lo profano ( $F E: 53-5)$.

b. Con todo, lo sagrado es inestable y está dotado de una alta contagiosidad (FE: 455), lo que hace que se 'pose' $(F E: 328)$ en objetos variados y cambiantes que actúan sólo como sus símbolos ( $F E: 331)$ a la espera de nuevas hierofanías.

c. Lo sagrado se genera y reproduce en experiencias de efervescencia colectiva $(F E$ : 313), cuyo formato res el de la experiencia ritual en general ya analizada.

d. Lo sagrado es expresivo de la sociedad que lo genera, que por su intermedio y gracias a esa hipóstasis accede a lo que le es más propio (las emociones grupales objetivadas) (FE: 319, 326, 603-4).

e. Lo sagrado, producto y expresión de prácticas colectivas, cumple la función de mantener el tono vital de la colectividad humana que lo genera y sustenta, ya que las religiones no suponen tanto un saber como un hacer conjunto ( $F E$ : 598), tienen por función "ayudarnos a vivir" ( $F E: 595)$ y se vertebran en una "fe" ( $F E$ : 615) que, más que como conjunto de creencias blindadas frente a la duda, hay que entender como confianza que genera seguridad e impulsa a actuar (FE: 615).

Esta versión comprimida de lo que Durkheim, en distintos pasajes de $F E$ y enfrentando distintos problemas, va fijando como semántica de lo sagrado permite abordar la pregunta sobre qué le agrega postular su ambigüedad y con qué consecuencias se suma a sus otras notas distintivas. ¿Qué significa la ambigüedad predicada de lo sagrado? ¿Supone una novedad relevante? ¿Cómo casa con la semántica que se va fijando a lo largo de $F E$ ? ¿Hasta qué punto el deseo de completar su teoría sistemática de lo religioso-sagrado como hecho social recurriendo a la ambigüedad no genera problemas a la sociología durkheimiana de la religión que ésta no puede solucionar?

La ambigüedad de lo sagrado no deja de arrastrar una significación realmente ambigua ${ }^{12}$. Un rastreo de $F E$ permite entenderla, ciertamente, como (a) ambigüedad o equivocidad en sentido estricto (dificultad para fijar un significado propio y claramente delimitado), pero también como (b) ambivalencia (dos caras contrapuestas que se dan a la vez en las cosas o experiencias sagradas), como (c) simple dualidad (dos caras distinguidas y separadas netamente por una frontera de modo que se está o más acá o más allá de la frontera) y como (d) inestabilidad (se pasa de una cara a la otra de forma continua o impredecible). Sin ir más allá, propongo que en el uso del concepto se transita, sin mostrarse plena consciencia de ello, entre estos planos de significación, mezclándolos a veces.

Durkheim fija lo que, en seguimiento de Robertson Smith, entiende por ambigüedad de la siguiente manera:

"Las fuerzas religiosas son de dos tipos. Unas son bienhechoras, guardianas de orden físico y moral, dispensadoras de la vida, de la salud, de todo lo que los hombres estiman [...] El respeto que inspiran se mezcla con el amor y el reconocimiento [...] Hay, por otro lado, poderes malos e impuros, productores de desórdenes, causa de muertes, enfermedades, instigadoras de sacrilegios. Suscitan en el hombre sentimientos de un temor en el que se entremezcla generalmente el horror" (FE: 584-85).

La ambigüedad de lo sagrado supone, pues, la coexistencia de fuerzas sagradas maléficas y benéficas, cuyas relaciones son complejas. Al caracterizarlas, Durkheim sigue el modelo de la distinción sagrado/profano: también en este caso, y aunque lo sagrado-fasto y lo sagrado-nefasto sean manifestaciones de lo sagrado que se enfrentan en igual medida a lo profano ( $F E: 586)$, entre las dos variantes hay un marcado antagonismo ( $F E$ : 585-6) y un frecuente transmutarse, ligado, por un lado, a la arbitrariedad

\footnotetext{
${ }^{11}$ Reproduzco la tan comentada definición: "Una religión es un sistema solidario de creencias y prácticas relativas a cosas sagradas, es decir, separadas, interdictas; creencias y prácticas que unen en una misma comunidad moral, llamada Iglesia, a todos sus adherentes" (FE: 65).

${ }^{12}$ Durkheim utiliza también el término ambigüedad para dar cuenta de las fuerzas religiosas en general (FE: 318-9), los seres míticos (FE: 337) o de los rituales (FE: 552).
} 
de las encarnaciones de lo sagrado y, por el otro, a su movilidad-contagiosidad ( $F E$ : 587-8). Sintetizando:

"Lo puro y lo impuro no son, pues, dos géneros separados, sino dos variedades de un mismo género que comprende a todas las cosas sagradas. Lo sagrado tiene dos tipos, uno fasto y otro nefasto, y entre esas dos formas opuestas no sólo no hay solución de continuidad, sino que además un objeto puede pasar de la una a la otra sin cambiar de naturaleza. Con lo puro se hace lo impuro y viceversa. La ambigüedad de lo sagrado consiste en la posibilidad de esas transmutaciones" (FE: 588).

Parece, pues, que el juego de relaciones entre lo sagrado puro y lo sagrado impuro se despliega siguiendo el modelo que brindan las relaciones generales entre lo sagrado y lo profano. Lo distinguido (sagrado) se distingue adicionalmente (fasto/nefasto), siguiendo los mismos criterios y multiplicando así la lógica de la 'dualización' de la realidad tan propia del discurso de $F E^{13}$. Llama, con todo, la atención que no se proceda simétricamente. En efecto, en $F E$ no se plantea nunca la posibilidad de que, a su vez, lo profano se distinga interiormente en dos realidades antagónicas ${ }^{14}$. ¿Por qué entonces recibe lo sagrado una aplicación recursiva de la distinción que lo constituye, mientras lo profano se mantiene indistinto? Dos razones parecen inmediatamente pertinentes: la primera es que la noción de lo profano resulta en el discurso de $F E$ residual y derivada ${ }^{15}$, limitada a designar a todo lo que no es sagrado, convirtiéndose en un cajón de sastre cuya complejidad propia no es considerada ni ordenada; la segunda es que la distinción está provocada por los resultados obtenidos en el análisis de los ritos piaculares y su contraposición típica de las potencias sagradas malevolentes y benevolentes: al antagonismo de fuerzas o dioses es lógico que corresponda un antagonismo de sacralidades.

A estas dos razones inmediatas conviene agregar otra de orden más general y que lleva más lejos. Durkheim considera que, distinguiendo la doble cara de lo sagrado, su noción no sólo gana en complejidad, sino sobre todo en realismo. Esta conside- ración aparece al menos en dos ocasiones en las que se aborda el tema general de la ambigüedad. En una de esas ocasiones se viene a decir que no siendo la vida social monótona y homogénea, sino animada por estados emocionales contrapuestos, también lo tiene que ser aquello que más propiamente la expresa, como es la experiencia de lo sagrado. De este modo la llamada ambigüedad de lo sagrado refleja con realismo los estados emocionales fundamentales de la vida social:

"Los dos polos de la vida religiosa corresponden a los dos estados opuestos por los que trascurre toda la vida social. Entre lo sagrado fasto y lo sagrado nefasto hay el mismo contraste que entre los estados de euforia y disforia colectiva. Pero como ambos son en igual medida colectivos, hay un íntimo parentesco natural entre las construcciones mitológicas que los simbolizan. Los sentimientos puestos en común varían desde el extremo abatimiento a la extrema alegría, desde la irritación dolorosa al entusiasmo extático" (FE: 591).

De alguna manera, el argumento se aproxima al que hace inteligible la otra distinción fundacional que separa lo profano de lo sagrado y que, según se analiza recogiendo ideas de Marcel Mauss $(F E$ : 307 ss.), también refleja una oscilación o variación intrínseca a la vida social entre estados de fisión y de fusión social, con sus concomitancias emocionales. Como se podrá comprobar más adelante, esta semejanza de argumentos sobre las bases realistas de ambas distinciones no deja de tener interés, pues arrastra semejantes dificultades analíticas.

Por otro lado, la ambigüedad de lo sagrado se justifica atendiendo al realismo propio de las religiones que, a lo largo de la historia, se han caracterizado por recoger en sus panteones todas las miserias de la vida en sociedad, sin ocultar sus aspectos menos edificantes:

"La religión es realista a su manera. No hay fealdad física o moral, no hay vicio, no hay mal que no haya sido divinizado. Hay dioses del robo y de la astucia, de la lujuria y de la guerra, de la enfermedad y de la muerte [...] Satanás es un elemento esencial del sistema cristiano; es un ser

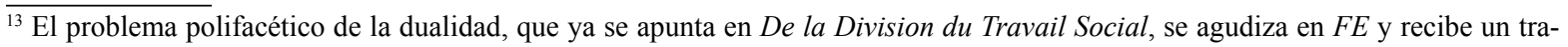
tamiento monográfico en un escrito importante dos años después (Durkheim 1914). Merecería en sí un estudio sistemático, que no se puede emprender aquí. Sobre el tema, véanse Cladis (2008), Rawls (2004: cap . 2), Ramp (2003), Shilling \& Mellor (1998). Una lectura en profundidad del tema llevaría a plantear las relaciones de la sociología durkheimiana con lo trágico.

${ }^{14}$ Sobre el hecho ha llamado la atención Rosati (2005: 72-3), que sin embargo no lo desarrolla.

${ }^{15}$ También se podría decir que lo profano no está marcado, mientras lo sagrado sí. En razón de esto, como lo presenta Scubla (2008: 18) su relación se podría representar según el siguiente esquema: Profano o [Sagrado y (Puro o Impuro)].
} 
impuro, pero no profano. El anti-dios es un dios, ciertamente inferior y subordinado, pero dotado de amplios poderes; incluso es objeto de ritos, por lo menos negativos [...] Lejos de ignorar la sociedad real y hacer abstracción de ella, la religión es su imagen; refleja todos sus aspectos, incluso los más vulgares y repulsivos" (FE: 601). Hasta aquí las propuestas de Durkheim y las ventajas que se obtienen apostando por una noción de lo sagrado con la suficiente complejidad como para admitir su doble cara y las ambivalencias-ambigüedades-inestabilidades. Pero esas ventajas no se consiguen gratis, sino al precio de generar dificultades serias.

En efecto, si lo sagrado es doble (fasto y nefasto) y si, como se ha comprobado, entra de lleno en la experiencia del mal (lo nefasto, de mal augurio, airado, vengativo, destructivo, desgraciado, malevolente, maligno, etc.), entonces sería coherente concluir que, al igual que el bien, el mal participa plenamente en lo sagrado, está lleno de sacralidad. Durkheim se convertiría así en Bataille o se le aproximaría sustancialmente ${ }^{16}$. La suya sería una sociología del mal que tendría también por objetivo central desvelar y hacer inteligible "la part maudite du sacré" (Arppe 1995), eso que Mauss (1968-9, vol 3: 493) llamaba "le côté sombre de l'humanité" que, a su entender, tanto había interesado al durkheimiano Hertz ${ }^{17}$-para Riley (1999), un durkheimiano cargado de lecturas de Nietzsche, que se desplazaba hacia una sociología durkheimiano-nietzscheana que su heroica muerte en el campo de batalla de Marchéville en 1915 frustró $^{18}$.

Si se llega plena y consecuentemente a esta conclusión y se asume la tesis central durkheimiana que asegura que lo sagrado no es sino expresión de la sociedad o la sociedad transfigurada, entonces habría que concluir que la sociedad misma está vertebrada por una tensión constitutiva que la hace fuente del bien y del mal. La llamada ambigüedad de lo sagrado iría entonces de la mano de la ambigüedad de lo social (Pickering 2009: 129; Arppe 1995). Esta conclusión llevaría a afirmar la ambivalencia constitutiva de lo social y, en consecuencia, a mostrar el conflicto, la lucha, el desgarro como algo que le es propio y definitorio, no como carencia, defecto o patología. No se trataría de repetir el cansino tópico liberal que enfrenta individuo y sociedad-Estado, sino de algo más interesante y sutil: la ambivalencia de lo social, la co-presencia de fuerzas constructivas y destructivas en su seno, etc. -lo que, por lo demás, pondría a Durkheim en la estela de la sociología del Simmel (1988) que enfatizaba la ambivalencia como rasgo constitutivo de lo social.

¿Llega a estas conclusiones Durkheim? ¿Despliega coherentemente su análisis hasta alcanzar y aceptar este resultado? Es obvio que no. La llamada ambigüedad de lo sagrado resulta de una distinción que discrimina y degrada una de las caras a favor de la otra, del mismo modo que la distinción fundacional sagrado/profano, que en principio es intrínseca a lo social, privilegia a una de las caras, lo sagrado, identificándola con lo social propiamente dicho, y acaba exiliando la esfera de lo profano a un espacio inconcreto (¿lo social degradado?, ¿lo pseudo-social?, ¿lo cuasi-social?, ¿lo asocial?, ¿lo puramente individual?). En consecuencia, no queda claro qué distingue la distinción, dónde opera, qué espacio segrega. En el caso de la distinción fasto/nefasto ocurre lo mismo. Lo sagrado fasto es privilegiado como encarnación de lo social, mientras lo sagradonefasto es secundarizado, desplazado, marginado (Arppe 1995: 213). Durkheim es, en este sentido, la inversión de Bataille: si éste enfatiza la parte maldita de lo sagrado a costa de la bendita, aquél subraya la parte noble hasta arrinconar o ningunear la otra (Riley 2005; Ramp 2008a y 2008b).

Es más: ya se pudo comprobar en páginas anteriores que a la hora de dar cuenta de la parte siniestra de lo sagrado Durkheim la caracteriza como fruto de una experiencia doble y contradictoria - lo que no es el caso cuando se trata de la parte luminosa o positiva. En efecto, si lo sagrado objetiva siempre experiencias emocionales, en el caso de lo sagrado

\footnotetext{
${ }^{16}$ Sobre las relaciones entre la sociología de lo sagrado de Durkheim y Bataille se pueden consultar los trabajos de Arppe(1995 y 2009), Ramp (1998, 2003, 2008a y 2008b), Riley (2005) y Stedman Jones (2001).

${ }^{17}$ En otro texto de 1922 que introducía la publicación del trabajo inédito de Robert Hertz sobre el pecado y la expiación, sostenía Mauss que como Hertz "no carecía ni de humor ni de fantasía -ni de un cierto pesimismo- se preocupó por comprender precisamente los lados sombríos y siniestros de la mentalidad humana" (Mauss1968-9, vol. 3: 511; énfasis RRT).

${ }^{18}$ Los análisis más interesantes de Hertz sobre el tema aparecen en sus trabajos sobre el duelo (Hertz 1907) y la preeminencia de la mano derecha (Hertz 1909), recogidos ambos en español en Hertz (1990). He llamado la atención sobre ellos en Ramos (1991). Sobre la relevancia de los estudios de Hertz en este campo véanse los trabajos de Parkin (2008) y sobre todo de Riley (1999). Para un trabajo sistemático sobre el problema del mal en la sociología durkheimiana sería preciso abordar con detenimiento la obra de Hertz, cosa que no se puede hacer en el marco de este artículo.
} 
nefasto esas experiencias son de dos tipos: por un lado, experiencias depresivas y tristes; por el otro, experiencias de consuelo y revitalización que son constitutivas del ritual piacular. No ocurre así con las experiencias de fondo objetivadas en lo sagrado fasto, que son homogéneas y tan sólo responden a la euforia social. En consecuencia, hay una clara asimetría entre las experiencias sociales de fondo que generan la ambigüedad de lo sagrado: en el caso de los poderes siniestros esa experiencia es, en el fondo, contradictoria, por lo que es lógico que lo maligno no emerja de forma nítida e incondicional. Resulta así, si se atiende a las prácticas emocionales que lo generan, un sagrado nefasto heterogéneo, contradictorio o edulcorado.

¿Qué queda entonces del supuesto realismo de las religiones que tan bien casaba con la ambigüedad de lo sagrado? Poco, si por tal realismo se entiende su transparencia a la hora de hacer claramente visibles, sin velos ni tapujos, los aspectos siniestros o negativos de la realidad social, tan sagrados y trascendentes como los otros.

$\mathrm{Y}$, en efecto, el realismo acaba siendo demediado. Viéndose deslizar hacia terrenos contradictorios con las señas de identidad de su sociología en general y de su sociología de la religión en particular, Durkheim propone una curiosa concepción del realismo religioso: un realismo que incorpora lo ideal como real. No hay, aparentemente, contradicción en una propuesta así, pero sólo al precio de un juego con las palabras que las hace poco razonables. En efecto, al hilo de volver a destacar el realismo de las religiones, insiste en que el idealismo es un producto natural (y por lo tanto real) de la vida religiosa porque "es un producto natural de la vida social" (FE: 603). De ahí que la realidad que queda en ellas reflejada aparezca "agrandada, transformada, idealizada" (FE: 601), resultando que "el mismo mal queda como sublimado e idealizado" (FE: 601). ¿En qué se convierte el mal social cuando es sublimado e idealizado? En un mal que siempre está en fuga: un Satán que siempre pierde su batalla y acaba expulsado; un mal reconocido, pero para asegurar su estatuto subordinado y su derrota final.

La apoteosis de la luz y la victoria -asegurada onto-teológicamente y siempre repetida en la historia- de lo sagrado fasto sobre lo sagrado nefasto se muestra en una reflexión sobre el tema que aparece ya en las páginas finales de $F E$. Se insiste, de nuevo, en el realismo religioso, pero se trata, por utilizar categorías dramáticas, del realismo de la comedia cuando se dedica a disolver la tragedia aparente de la realidad. El texto dice lo siguiente:
"Lejos de ignorar la sociedad real y hacer abstracción de ella, la religión es su imagen; refleja todos sus aspectos, incluso los más vulgares y repulsivos. Todo se encuentra en ella y si suele ocurrir que en ella el bien triunfe sobre el mal, la vida sobre la muerte, los poderes de la luz sobre los poderes de las tinieblas, es porque no ocurre de otra forma en la realidad. Pues si la relación entre esas fuerzas estuviera invertida, la vida sería imposible; pero, de hecho, la vida se mantiene e incluso tiende a desarrollarse" (FE: 601; énfasis RR).

Más tarde habrá ocasión de volver sobre este texto que recoge bien la solución durkheimiana al problema de la teodicea. Queda en cualquier caso clara la demediación de lo sagrado nefasto, incapaz de ganar nunca la carrera de la historia o de la realidad.

Y no se trata tan sólo de un realismo demediado, desdramatizado, que asegura que al final las luces triunfan sobre las tinieblas, sino además de un realismo basado en la exteriorización y exorcización del mal o, dicho de otra manera, de un realismo asocial, que sitúa al mal por fuera de la esfera de lo social. En efecto, las desgracias que dan lugar a las respuestas rituales se refieren siempre a "circunstancias que atraviesa la sociedad" (FE: 589), provocadas exógenamente. El mal viene de fuera: la muerte biológica, la sequía, la inundación, los animales que desaparecen, el robo de los objetos sagrados, etc. Internas son sólo las emociones que suscita en el grupo y que se objetivan en las fuerzas sagradas. Durkheim, como comenta atinadamente Pickering (2009: 129), entra en contradicción consigo mismo, pues explica un hecho social (los ritos piaculares) a partir de fenómenos extra-sociales (desastres naturales). En consecuencia, el mal no es social más que como reacción ritual que lo canaliza en la secuencia dueloexpiación. El sociologismo de Durkheim se convierte en su antónimo, el naturalismo: es el espectáculo dramático de la naturaleza el que desencadena una respuesta emocional que cuando se ritualiza se hace colectiva, se socializa; la religión que aborda el mal es un naturalismo ritualizado. De esta manera el mal es asocializado, lo que convierte en irónica una sociología del mal que lo quería reducir a hecho social.

La conclusión que se alcanza retrata, pues, el extraño viaje analítico de la ambigüedad de lo sagrado. Abierta al reconocimiento del mal como fuerza social de primer orden, acaba demediándolo o exteriorizándolo. El mal que aparecía en primer plano ha de huir derrotado por el fondo del escenario. 


\section{EL PROBLEMA DE LA TEODICEA}

En 1710 publica Leibniz su Teodicea con un título muy expresivo: Essai de Théodicée sur la bonté de Dieu, la liberté de l'homme et l'origine du mal (Leibniz 1969). Leibniz se erige en abogado de Dios, pero para abordar un problema tan viejo como la humanidad y que, como ya destacara Weber (1983: 196 ss.), no precisa del surgimiento de las religiones éticas o del monoteísmo para que resulte demandante y exija soluciones. Es el problema de explicar y justificar que los seres humanos sufran múltiples males (físicos, morales, sociales) repartidos, además, de forma inconstante, desigual e injusta. Desde el punto de vista de una religión como la cristiana el problema es apremiante y los elementos que en él se relacionan aparecen ejemplarmente enunciados en el título del ensayo de Leibniz: la bondad de un Dios que es, además, Sabio y Todopoderoso, la Libertad del hombre y la presencia del Mal. Pero el problema va más allá de la esfera de la religión, traduciéndose en sociodiceas puramente laicas; la sociología de Durkheim es una de ellas. Se trata, además, de un problema que sigue teniendo una enorme relevancia en los debates actuales sobre filosofía moral y social ${ }^{19}$ y que, aunque de forma minoritaria, es reivindicado también en la sociología contemporánea ${ }^{20}$.

Sin intentar reconstruir de forma completa la solución que le da Leibniz, es legítimo reducirla a la utilización del Principio Consecuencial. Este principio permite observar, explicar y justificar las cosas que ocurren en el mundo en función de sus consecuencias sistémicas o a largo plazo, abogando así por la escasa relevancia de lo que ahora son o suscitan en el momento de su aparición y apostando por atender a sus consecuencias sistémico-temporales. Desde este punto de vista, el mal (moral, físico o social) que sufrimos los humanos puede estar justificado a ojos de la sabiduría consecuencial de Dios en razón de consecuencias positivas que somos incapaces de ver nosotros, criaturas finitas. Lo malo puede ser así lo mejor dentro de un mundo posible (y en razón de lo que en él es com-posible) o un simple medio para conseguir ulteriormente un bien que revierte en la armonía del cosmos y justifica la sabiduría de su creador.

Baste con esta especificación de la propuesta, que en otra ocasión he abordado con algún detenimiento (Ramos 2002: 1013-6). Es oportuno en este contexto llamar la atención sobre el hecho de que esa especulación que parece sólo pertinente en el campo de la teología o la filosofía moral lo es doblemente para dar cuenta de la sociología y, especialmente, de la sociología durkheimiana del mal que vengo explorando. Doblemente pertinente porque, por un lado, el problema de la teodicea ha concitado la atención de algunas de las sociologías clásicas más influyentes, entre las que se encuentra la durkheimiana; pero pertinente también porque la solución del problema en términos del principio consecuencial proporciona un modelo de análisis de los fenómenos sociales por el que apostó decididamente Durkheim. Ambas cosas están muy unidas: enfrentar el problema de la teodicea (sin problematizarlo o disolverlo en términos de una más terrena algodicea ${ }^{21}$ ) y utilizar el principio consecuencial van típicamente de la mano, siendo éste la solución más recurrente de aquél.

¿Cuáles son las propuestas de Durkheim? Es claro que el tema de la teodicea le es cercano, pues a su ya comprobada atención al problema religioso del mal se agrega su interés por el sufrimiento como experiencia social de primer orden ${ }^{22}$. En ambos casos, no sólo se da cuenta de su presencia y se propone una explicación, sino que también se procede a su justificación. Estamos, pues, en el espacio de la teodicea.

Sabido es que a Weber (1969 y 1983: 196 ss.) tampoco le era indiferente (Cherkaoui 2007), pero su punto de vista difería en lo sustancial del de Durkheim. Esta comparación proporciona claves importantes. En efecto, el problema dominante que enfrentan los análisis weberianos sobre las distintas teodiceas que se han sucedido en la historia de las religiones (Weber 1969) es el problema del sentido.

\footnotetext{
$\overline{{ }^{19} \text { Obras actuales }}$ de referencia sobre el tema del mal y la teodicea son las de Berstein (2005), y Safranski (2000). Una buena selección de los debates sobre el mal a lo largo de la historia es Larrimore (2001). En Lara (2003) y en Muguerza \& Ruano de la Fuente (2008) se recogen debates actuales sobre el tema.

${ }^{20}$ Por ejemplo en Cherkaoui (2007), Das (1997), Morgan \& Wilkinson (2001), Musick (2000), Pickering (2004).

${ }^{21}$ De algos (dolor) y diké (justicia); por lo tanto, literalmente, justificación (moral) del dolor. El concepto es introducido por Sloterdijk, que lo aclara de la manera siguiente: «Algodicea significa tanto como una interpretación metafísica y dadora de sentido del dolor. En la modernidad aparece en lugar de la teodicea como su inversión. En ésta la formulación era: ¿cómo se pueden conciliar el mal, el dolor, el sufrimiento y la injusticia con la existencia de Dios? Ahora la pregunta viene a ser ésta: si no hay Dios, si no hay un contexto de sentido superior, ¿cómo se puede soportar el dolor?». (Sloterdijk 1989: 291).
} 
Weber se pregunta en qué consistieron las soluciones intelectuales (sentido) que se fueron brindando al problema de la teodicea y cuáles fueron sus consecuencias en el campo de la práctica. La secuencia es: Problema del mal $\rightarrow$ Asignación de Sentido $\rightarrow$ Consecuencias Prácticas (morales, económicas, políticas, etc.). El análisis parte, pues, de la primacía del Sentido para llegar al problema de la Acción. El trayecto de Durkheim es justamente el inverso. Tal como lo aborda, el problema de la desgracia o, más ampliamente, el problema del sufrimiento genera inmediatamente una respuesta práctica en forma de rituales densamente emocionales para alcanzar, sólo después, una explicación que confiera sentido al mundo práctico ya generado. La secuencia es: Problema del mal $\rightarrow$ Respuesta ritual $\rightarrow$ Asignación de sentido a lo que se hace.

En efecto, para Durkheim el problema de la teodicea es un problema del hacer, no del decir -de acuerdo, por lo demás, con la hipótesis central en su sociología de la religión que asigna siempre primacía a la acción. El mal y el sufrimiento sólo se pueden enfrentar y justificar en términos de prácticas colectivas. El mundo no es un objeto opaco a contemplar, sino un entorno hostil del que nos protegernos hermanados, en grupo, para adquirir confianza y estar a salvo.

Hemos podido ya comprobar que los ritos piaculares, en su despliegue desde el duelo a la plena expiación, resuelven y disipan el problema reconstituyendo la amenazada vitalidad del grupo. El mal del mundo es finalmente disuelto por medio de prácticas rituales. Son las que nos devuelven las ganas de vivir y nos aseguran la salvación. Lo mismo ocurre con los ritos ascéticos que enfrentan y resuelven prácticamente el problema del sufrimiento. A su análisis se dedican en $F E$ (427-464) un buen número de páginas. A diferencia del mal que, como se ha comprobado, siempre es exógeno, el sufrimiento no es algo de lo que los rituales tengan siempre que librar, sino por el contrario algo que pueden tener por función producir. Es justamente la función específica de los ritos ascéticos, que separan dolorosamente lo profano de lo sagrado; de ellos dice Durkheim que "el dolor es su condición necesaria" (FE: 446). Es, ciertamente, un dolor ritualizado, pero provocado, buscado ¿Por qué esa búsqueda ritual del sufrimiento? Porque los rituales ascéticos dan por supuesto que sus prácticas dolorosas son "generadoras de fuerzas excepcionales" ( $F E: 451)$, que no son otras que las que confiere a sus miembros el grupo que se constituye justamente por su mediación. De esta manera, gracias al dolor ritualizado acabamos enfrentando con más seguridad las relaciones con un mundo hostil porque las enfrentamos formando parte de un grupo compacto. El dolor y el sufrimiento que activan los ritos ascéticos son la condición para la humanización -por vía ritual- del ser humano. Durkheim no duda en construir una oda arrebatada al dolor, elogiando al hombre como criatura que sabe sufrir y en eso cifra su diferencia:

"Es en el modo en que se desprecia el dolor como mejor se manifiesta la grandeza del hombre. Nunca se eleva con más brillo por encima de sí mismo que cuando doma su naturaleza hasta el punto de hacerla seguir una vía contraria a la que escogería espontáneamente. En esto se separa del resto de las criaturas que se dirigen ciegamente a la llamada del placer; por esto, consigue un lugar aparte en el mundo" (FE: 451).

La propuesta firme de $F E$ es, pues, que las religiones han resuelto siempre en términos de prácticas el problema de la teodicea, conformando rituales que permiten enfrentar las experiencias del mal y del sufrimiento. Esta primacía de la práctica lo es de la práctica colectiva ritualizada y va de la mano de la asignación de un protagonismo de primera fila a las emociones. Las religiones con las que los humanos se protegen de un entorno hostil no pretenden proporcionarles respuestas sobre el sentido del mundo, sino asegurarlos ontológicamente, darles confianza, proporcionarles deseos de vivir y superarse, conferirles fe en su preservación o puesta a resguardo del mal o de un sufrimiento sin sentido. Y no se trata de un objetivo secundario, sino de la verdadera finalidad o función de las religiones:

"La verdadera función de la religión no es hacernos pensar [...], sino hacernos actuar, ayudarnos a vivir. El fiel que se ha comunicado con su dios no es sólo un hombre que contempla verdades nuevas ignoradas por el que no cree, sino un hombre que puede más. Siente en sí una mayor fuerza tanto para soportar como para vencer las dificultades de la vida. Está como elevado por encima de las miserias humanas porque se eleva

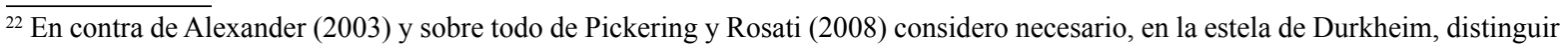
el problema del sufrimiento del problema del mal. El concepto amplio de teodicea que estoy utilizando permite contemplar ambas experiencias sociales, aunque se distingan conceptual y ritualmente
} 
por encima de su condición de hombre; se siente a salvo del mal, con independencia de cuál sea la forma en la que se lo representa. El primer artículo de toda fe es la creencia en la salvación por la fe"(FE: 595; cursiva RR).

En definitiva, y a tenor de un texto tan rotundo, el objetivo de las religiones, desde las más primitivas hasta las más complejas y evolucionadas, es resolver el problema de la teodicea. No es un problema más, sino su problema fundamental. El descubrimiento de Durkheim consiste en mostrar que lo hacen ritualmente, es decir, por medio de prácticas colectivas repetitivas emocionalmente cargadas.

El problema de Leibniz es, pues, el problema de Durkheim. Pero además la solución leibniziana es también, en lo sustancial, la solución de Durkheim. Esa solución se construye sobre el principio consecuencial que postula una infinita Sabiduría que conoce las consecuencias sistémicas y a largo plazo de los acontecimientos y así los justifica. Quítese la referencia a una Sabiduría divina y atengámonos a la reproducción de la estructura social; estaremos entonces abandonando el espacio de la teología para desembarcar en el de la sociología durkheimiana. El funcionalismo durkheimiano es un consecuencialismo estricto. En él el principio consecuencial mantiene su identidad básica, pero adaptado al espacio de lo social y atendiendo más a la prácticas que a las mentes.

Esa adaptación se había bosquejado ya al poco de enunciarse, allá en la primera mitad del siglo XVIII, en tierras de Europa. Mandeville (1997), en el campo de las relaciones entre la moral y la economía, y Vico (1985), en el de las relaciones de la moral, la civilización y la historia, habían esbozado ya nuevas aplicaciones al principio consecuencial. Adam Smith, a pesar de sus críticas a la "sofistería ingeniosa" de Mandeville (Smith 1997: 543), hace otro tanto al postular unas manos ocultas y benéficas que rigen los destinos beneficiosos para la sociedad de las acciones egoístas de los seres humanos ${ }^{23}$.

El funcionalismo de Durkheim es una adaptación más del principio consecuencial; una adaptación que no sólo recoge una orientación metodológica, sino que arrastra consigo la metafísica de fondo que presupone un mundo amable por detrás de su careta de hostilidad; un mundo en el que todo ocurre para preservarlo de lo que sus actores hacen creyendo saber lo que hacen, pero sin saberlo propiamente, pues sólo el sabio que realiza el análisis funcional podrá mostrar que lo que ocurre, provocando el mal o el sufrimiento en los actores inmediatos, no hace sino cooperar al mantenimiento del todo para beneficio de todos.

\section{CONCLUSIONES}

Gaston Richard (¿1939?), un antiguo durkheimiano que acabó alejándose de la ortodoxia de la escuela, reprochaba a la sociología de Durkheim estar por debajo de su objeto de análisis, la religión. Su argumento era que siendo la teodicea el problema que las religiones abordan y solucionan, la reducción social de la religión que proponía Durkheim acababa por hacerlo inabordable y consecuentemente irresoluble ${ }^{24}$.

El problema que propone Richard no es trivial, ni se puede despachar de un plumazo. No se trata tanto de que la sociología durkheimiana de la religión aborde o no el problema de la teodicea al estudiar las distintas religiones; se trata más bien de dilucidar si el principio de inteligibilidad que propone permite o no dar cuenta de él. El principio de inteligibilidad que Durkheim propone es aquel que dice que las religiones son reductibles genética, expresiva y funcionalmente a la sociedad -con independencia de qué se entienda por tal ente. La objeción que plantea Richard sería entonces que la reducción de la experiencia religiosa a experiencia social impide abordar y dar solución al problema real, humano e ineliminable de la teodicea.

¿Se le puede hacer este reproche a la sociología de la religión durkheimiana? No sería justo: puede convencernos o no la solución brindada, puede incluso parecernos el de la teodicea un falso problema, pero en ningún caso se pude sostener que Durkheim abordara el estudio de la religión sin tomarlo seriamente en consideración, ni, sobre todo, que el marco de inteligibilidad que proponía fuera incapaz de retenerlo.

En efecto, Durkheim proponía la conversión del problema de la teodicea en su equivalente tras la muerte de dios, es decir, en el problema de la socio-

\footnotetext{
${ }^{23}$ Presento de forma harto sintética argumentos que he desarrollado en otros trabajos ya publicados, a los que me remito. Sobre Mandeville y Vico véase Ramos (2002) y la bibliografía allí utilizada; sobre Adam Smith, véase Waterman (2002) y Ramos (2001) y la bibliografía allí .citada.

${ }^{24}$ Sobre Gaston Richard, véase Pickering (1979 y 2004).
} 
dicea. En ningún caso sostenía que fuera un falso problema o un problema extraño a la sociología o un problema a disolver optando por un discurso radicalizado y consecuente sobre la muerte de dios -en los términos de un Nietzsche, por ejemplo (Sloterdjik 2000: 156 y ss.). Lo novedoso de su propuesta es que la pregunta por la explicación y justificación del mal y el sufrimiento ya no interpela a dios, sino a la sociedad; en consecuencia, el discurso que justifica no es ya una defensa de dios, sino de la sociedad. También el remedio, aunque ritual, nada tiene que ver con dios y todo con la sociedad. Éste es el sentido hondo de la sociología durkheimiana de la religión.

Durkheim no era un innovador radical al proponer este giro; más bien formaba parte de la corriente principal de la modernidad. Desde la Ilustración se ha venido trabajando con el equivalente laico del problema de la teodicea (Cassirer 1972: 177 y ss.). Las filosofías de la historia de Kant y de Hegel mostraron que tal traducción era posible: sería el tiempo todavía no trascurrido ni vivido, el futuro, el que resolvería el problema del mal gracias a la "insociable sociabilidad" (Kant 1784: 46) del hombre o al "ardid de la razón" (Hegel 1980: 97) en la historia. El evolucionismo social del XIX transitó en el mismo sentido. Y lo mismo hizo la economía política que también creía en el mercado -y sigue haciéndolo, como muestra Dupuy (1992: 241 ss.) al analizar las propuestas de Hajek- como el gran conversor de los egoísmos en altruismos, garante fiable de la creación del mejor de los mundos posibles. En todos estos casos se hace a la luz una sociodicea propiamente dicha que justifica en términos sociales la justicia del mal.

La nueva sociología de Durkheim mantuvo ese derrotero. Su objeción al individualismo metodológico, según la cual no todo es contractual en el contrato (Durkheim 1893: 189, 207), y el consiguiente señalamiento de lo social o la sociedad como el nuevo espacio a abordar científicamente no supuso renunciar a enfrentar y resolver el viejo problema de la teodicea. La sociodicea durkheimiana lo expresa claramente: el sufrimiento forma parte del proceso de construcción social de la persona humana; podemos execrarlo individualmente, pero socialmente es una condición de la hominización y la civilización; por su parte, el mal forma parte de nuestra experiencia del mundo, pero también podemos derrotarlo prácticamente y resignificarlo socialmente. La so- ciología se convierte en una sociodicea porque desvela, con la ayuda de la variante funcionalista del principio consecuencial, de qué modo el sufrimiento que como individuos sufrimos y el mal con el que nos acosa una naturaleza madrastra quedan disueltos o adquieren sentido gracias a las prácticas rituales, es decir, al formar parte de una sociedad constituida.

Ciertamente la sociodicea durkheimiana goza de la ventaja de estar libre del problema mayor de la teodicea de las religiones monoteístas. Me refiero a la contradicción imputable a un dios que crea el mundo y el mal a la vez. En la versión durkheimiana, al nuevo dios mortal llamado sociedad no se le puede imputar tal contradicción. En efecto, el mal es algo que la sociedad sufre, pero no engendra típicamente, pues la desgracia, tal como se pudo comprobar, viene siempre de fuera. La sociedad lo purga ritualmente, aunque no lo engendre. De ahí que podamos considerar la sociodicea durkheimiana como una desdramatización significativa de la teodicea tradicional.

Con todo, el optimismo social que la sostiene conecta explícitamente con un optimismo cósmico que convierte a la naturaleza madrastra en una amable matrona $-\mathrm{y}$ a la tragedia del mal en la comedia de la bella reconciliación. Y así, sostiene confiado Durkheim, si en las religiones suele ocurrir el triunfo del bien sobre el mal, de la luz sobre las tinieblas, "es porque no ocurre de otra forma en la realidad. Pues si la relación de esas fuerzas se invirtiera, la vida sería imposible" (FE: 601). La tesis es clara: la sociedad que ritualmente expía y limpia del mal y también ritualmente resignifica el sufrimiento participa en un plan cósmico en el que la vida está asegurada.

Éste es el marco o fundamento más amplio en el que cobra sentido la sociología del mal que $F E$ esboza y que en las páginas que anteceden se ha reconstruido en sus múltiples caras y conexiones. En sus obras anteriores, Durkheim se había interesado por lo que había denominado la patología social (Durkheim 1893, 1895 y 1897), una rama crucial de la sociología que daba cuenta de los desarreglos y el sufrimiento social. Su sociología del mal va algo más lejos, pues convierte al mal y al sufrimiento en parte ineliminable de toda vida social. Pero, al fin y al cabo, a pesar de los tonos pascalianos audibles en $F E$, esa atención mayor al mal va de la mano de la firme negación de lo trágico y de una sociodicea que enjuicia a la sociedad y la absuelve. 


\section{BIBLIOGRAFÍA}

AlexAnder, J.C. (2003): "Verso una sociologia del male. Al di là del senso comune della modernità sull'alternativa al 'bene"” en M.P. Lara (ed.), Ripensare il male : prospettive contemporanee. Roma : Moltemi, 2003: 267-306. [Traducción de "Toward a Sociology of Evil", in M. P. Lara, ed., Rethinking Evil, Berkeley: University of California Press 2001]

Aristóteles (1992): Poética. (Edición trilingüe de Valentín García Yebra). Madrid: Gredos.

Arppe, T. (1995): « Émile Durkheim et la part maudite du sacré » Sociétés 48: 209-218.

ARPPE, T. (2009): « Sorcerer's apprentices and the 'will to figuration' : the ambiguous heritage of the Collège de France" Theory, Culture and Society 26, 4: 117-45.

Bellah, R. N. (2011): Religion in human evolution: from the Paleolithic to the Axial Age. Boston (MA) y London: Harvard University Press.

Berger, P. (1971): El Dosel Sagrado. Buenos Aires: Amorrortu. [Ed. Original 1967].

BersteIn, R. J. (2005): El mal radical. Una indagación filosófica. Buenos Aires: Lilmod.

CAssirer, E. (1972): Filosofía de la Ilustración. México, FCE.

Cherkaoui, M. (2007): Good Intentions: Max Weber and the Paradox of Unintended Consequences. Oxford: Bardwell Pres.

Cladis, M. S. (2008): "Suffering to become human: a durkheimian perspective” en Pickering, W.S.F. y M. Rosati (eds.) Suffering and Evil: the durkheimian legacy. New York \& Oxford: Durkheim Press/Berghahn Books: 81-100.

Collins, R. (2009): Cadenas de interacción ritual. Barcelona: Anthropos.

DAs, V. (1997): «Sufferings, Theodicies, Disciplinary Practices, Appropriations» International Social Science Journal, vol. 49, no. 154 , pp. 563-572.

Dupuy, J-P. (1992): Le sacrifice et l'envie. Paris, Calman-Lévy.

Durkheim, É. (1893): De la Division du Travail Social : étude sur l'organisation des sociétés supérieures, París, Alcan. (Citas por la edición PUF, París, 1973.)

Durkheim, É: (1895): Les Règles de la Méthode Sociologique. París, Alcan. (Citas por la edición PUF, París 1973.)

Durkheim, É. (1897): Le suicide: étude de sociologie, París, Alcan. (Citas por la edición de PUF, París 1973.)

Durkheim, É. (1912): Les formes élémentaires de la vie religieuse: le systeme totémique en Australie, París, Alcan. (Citas por la edición PUF, París: 1968).

Durkheim, É. (1914): «Le dualisme de la nature humaine et ses conditions sociales» Scientia 15: $206-21$ (recogido en E. Durkheim, 1970. La science sociale et l'action, Parls, PUF, 1970 : 314-32).

Hegel, G.W.F. (1980): Lecciones sobre la filosofia de la historia universal. Madrid, Alianza.

Hertz, R. (1907) «Contribution a une étude sur la représentation collective de la mort » Année Sociologique X [recogido en Hertz 1990: 13-102]

Hertz, R( 1909): «La prééminence de la main droite. Étude sur la polarité religieuse » Revue Philosophique XXXIV [recogido en Hertz 1990: 103-133]

Hertz, R. (1990): La muerte y la mano derecha. Madrid, Alianza.

Jones, J.A. (1977): “On understanding a sociological classic“" America Journal of Sociology 83 (2): 279-319.

JonES, J.A. (1986): "Durkheim, Frazer, and Smith: The Role of Analogies and Exemplars in the Development of Durkheim's Sociology of Religion" American Journal of Sociology, vol. 92, no. 3, pp. 596-627.

Kant, I. (1784): "Idea de una historia universal en sentido cosmopolita" en I. Kant, Filosofia de la historia, México, F.C.E, 1978: 39-65.

LARA, M. P. (ed.) (2003): Ripensare il male : prospettive contemporanee. Roma : Moltemi. [Trad. de Rethinking Evil, Berkeley: University of California Press 2001]

Larrimore, M. (ed.) (2001): The Problem of Evil. A Reader. London, Blackwell.

LeIBnIz, G.W. (1969): Essais de Théodicée. Paris, Flammarion.

Luhmann, N. (1982): The Differentiation of Society. New York, Columbia University Press.

Mandeville, B. (1997): La fábula de las abejas o los vicios privados hacen la prosperidad pública. Madrid, FCE.

Mauss, M. (1968-9): Oeuvres. 3 volúmenes. Paris, Minuit.

Morgan, D. (2002): "Pain: the unrelieved condition of modernity" European journal of social theory5 3: $307-322$.

Morgan, D. \& Wilkinson, I. (2001): "The problem of suffering and the sociological task of theodicy" European Journal of Social Theory 4 (2): 199-214.

Muguerza, J. y RuAno, Y. (eds.) (2008): Occidente y el mal. Bilbao: Fundación BBVA. 
Musick, M. A. (2000): “Theodicy and Life Satisfaction among Black and White Americans" Sociology of Religion61, 3: 267-287.

Nussbaum, M. (1995): La fragilidad del bien. Fortuna y ética en la tragedia y la filosofia griega. Madrid: Visor.

PAdel, R. (2009): A quien los dioses destruyen: Elementos de la locura griega y trágica. Madrid: Sextopiso.

PARKIN, R. (2008): "Robert Hertz on suffering and evil: the negative processes of social life and their resolution" en Pickering, W.S.F. y M. Rosati (eds.) Suffering and Evil: the durkheimian legacy. New York \& Oxford: Durkheim Press/ Berghahn Books: 103-117.

PICKERING, W.S.F. (1979): “Gaston Richard: collaborateur et adversaire” Revue Française de Sociologie XX, 1: 163 - 182.

PICKERING, W.S.F. (2004): "Theodicy and Social Theory: an exploration of the limits of collaboration between sociologist and theologician", en Pickering, W.S.F. \& Mills, O. (eds.), Sociology and Theology. Alliance and Conflict, Leiden: Brill: 59-79.

PICKerInG, W.S.F. (2008). "Looking backwards and to the future" en Pickering, W.S.F. y M. Rosati (eds.) Suffering and Evil: the durkheimian legacy. New York \& Oxford: Durkheim Press/Berghahn Books: 163- 178.

Pickering, W.S.F. (2009): Durkheim's Sociology of Religion. Cambridge: James Clark and Co. [1 $1^{\mathrm{a}}$ ed. 1984].

Pickering, W.S.F. \& M. Rosati (eds.) (2008) Suffering and Evil: the durkheimian legacy. New York \& Oxford: Durkheim Press/Berghahn Books.

Ramos Torre, R. (1991): "Robert Hertz, La muerte y la mano derecha (reseña)" Revista Española de Investigaciones Sociológicas 54: 239-42.

Ramos Torre, R. (1999): La sociología de Émile Durkheim. Madrid, CIS.

Ramos Torre, R. (2001): "La más melancólica de las reflexiones. Simpatía, virtud y fortuna en La teoría de los sentimientos morales de Adam Smith" Política y Sociedad 37: 21-46.

Ramos Torre, R. (2002): "Sobre los orígenes del Principio Consecuencial: Leibniz, Mandeville y Vico" en AA.VV La sociedad: teoría e investigación empírica. Libro de homenaje a José Jiménez Blanco. Madrid. CIS: 1013-1025.

Ramos Torre, R. (2010): "La comunidad moral en la obra de Émile Durkheim" en P. de Marinis, G. Gatti e I. Irazuzta (eds.), La comunidad como pretexto. En torno al (re)surgimiento de las solidaridades comunitarias. Barcelona: Anthropos: 383-412.

RAMP, W. (1998): "Effervescence, differentiation and representation in The Elementary Forms" en N. J. Allen, W.S.F. Pickering \& W. W. Miller (eds.) On Durkheim's Elementary Forms of Religious Life. London: Routledge: 136-148.

RAMP, W. (2003): "Religion and the Dualism of the Social Condition in Durkheim and Bataille" Economy and Society, vol. 32, no. 1, pp. 119-140.

RAmp, W. (2008a): "Transcendence, Liminality and Excess: Durkheim and Bataille on the Margins of 'Sociologie Religieuse"” Journal of Classical Sociology, vol. 8, no. 2, pp. 208-232, May 2008.

RAMP, W. (2008b): "Le malin génie: Durkheim, Bataille and the prospect of a sociology of evil" en Pickering, W.S.F. y M. Rosati (eds.) Suffering and Evil: the durkheimian legacy. New York \& Oxford: Durkheim Press/Berghahn Books: 118-135.

RAPPAPORT, R. (2000): Ritual y religión en la formación de la humanidad. Madrid: Cambridge University Press.

Rawls, A. W. (2004): Epistemology and practice. Durkheim's The Elementary Forms of Religious Life. Cambridge, Cambridge University Press. UCM Filosofía.

Richard, G. (1939 ?): Sociologie et théodicée: leur conflit et leur accord. Paris: Les Presses Continentales.

RiLey, A. T. (1999): "Whence Durkheim's Nietzschean Granchildren? A closer look at Robert Hertz's place in durkheimian genealogy" European Archives of Sociology 40, 2: 304-30.

RILEY, A. T. (2005) «'Renegade Durkheimism’ and the transgressive left sacred» en Alexander, J.C. y P. Smith (eds.) Cambridge Companion to Durkheim. Cambridge, Cambridge University Press: 274-304.

Rosati, M. (2005): “The Evil that Men Suffer: Evil and Suffering from a Durkheimian Perspective" Durkheimian Studies 11: $67-85$.

Rosat, M.(2008a): "Evil and collective responsibility: the Durkheimian legacy and contemporary debates" en Pickering, W.S.F. y M. Rosati (eds.), Suffering and Evil: the durkheimian legacy. New York \& Oxford: Durkheim Press/Berghahn Books: 136-147.

RosAti, M.(2008b): “Inhabiting No-Man's Land: Durkheim and Modernity” Journal of Classical Sociology, vol. 8, no. 2, pp. 233-261.

RuEl, M. (1998): «Rescuing Durkheim's 'rites' from the symbolizing anthropologists » en N.J. Allen, W.S.F. Pickering \&W.W. Miller (eds.) On Durkheim's Elementary Forms of Religious Life. London: Routledge: 105-115.

SAFranski, R.(2000): El mal o el drama de la libertad. Barcelona, Tusquets.

Scubla, L. (2008): "Préface" a Camille Tarot, Le symbolique et le sacré : Théories de la religion. Paris : La Découverte : 
13-24.

Segal, R. A. (2002) "Robertson Smith's influence on Durkheim's theory of myth and ritual” en Idinopulos, Thomas A. \& Brian C. Wilson (eds.) Reappraising Durkheim for the Study and Teaching of Religion Today. Leiden: Brill: 59-72.

Shilling, C. \& Mellor, P. A. (1998): "Durkheim, Morality and Modernity: Collective Effervescence, Homo Duplex and the Sources of Moral Action" The British Journal of Sociology, vol. 49, no. 2, pp. 193-209.

Simmel, G. (1988): "La moda” en G. Simmel, Sobre la aventura. Ensayos filosóficos. Barcelona, Península: 23-55.

SLOTERDIJK, P. (1989): Crítica de la razón cínica II. Madrid, Taurus.

SLOTERDIJK, P. (2000): El pensador en escena. El materialismo de Nietzsche. Valencia, Pre-Textos.

Sмітн, A. (1997): La teoría de los sentimientos morales. Madrid, Alianza.

Stedman Jones, S. (2001): "Durkheim and Bataille: constraint, transgression and the concept of the sacred" Durkheimian Studies/Études Durkheimiennes 7: 53-63.

STRENSKi, I. (1998): "Durkheim's bourgeois theory of sacrifice” en N.J. Allen, W.S.F. Pickering \& W.W. Miller (eds.): On Durkheim's Elementary Forms of Religious Life. London: Routledge: 116- 126.

Vico, G. (1985): Principios de la ciencia nueva. Barcelona, Orbis,(2 vol.).

WATERMAN, A M C (2002) “Economics as theology: Adam Smith's Wealth of Nations" Southern Economic Journal68, 4: 907-921.

Weber, M. (1969): “El problema de la teodicea” en Economía y Sociedad. México, FCE: 413-420.

WeBer, M. (1983): Ensayos sobre sociología de la religión I. Madrid, Taurus

WILKInSON, I. (2005): Suffering: a sociological introduction. Cambridge: Polity.

Wolf, K.H. (1969): "For a Sociology of Evil”, Journal of Social Issues, 1: 111-125. 